\title{
Design a Testing Battery to Measure the Performance of Some Basic Skills in Boxing for Students at the Faculty of Physical Education
}

\author{
Ahmed Rakha ${ }^{1}$ \\ ${ }^{1}$ Lecturer, Curricula and Teaching Methods Department, Faculty of Physical Education for (Men - Girls) in Port-Said, Port- \\ Said University, Egypt
}

\begin{abstract}
This research aims to extract testing battery to measure the performance of some basic skills in boxing for students at the Faculty of Physical Education. The researcher identified all basic skills that involved in the course description of Boxing (1) for Second year, Faculty of Physical Education in Port-Said. And through reference survey he designed eight tests to measure these basic skills and proceed all scientific coefficients, Content validity, Stability, Intrinsic Validity and discriminatory ability which reached the required rate for conduct the factor analysis. One hundred students in second year in faculty of physical education in Port-Said responded to the proposed eight tests in the period from 16-17/3/2016. The researcher used (SPSS) software for conducting statistical treatments. In light of the factor analysis using components Principal method and after orthogonal rotation, extracted five factors represent five domains cover the basic skills as follows: (Lead hand Straight punch(Jab), Rear hand Straight punch (Cross), The speed of one combination punch, The speed of Jab-cross combination punches, Stance \& foot work). Consequently, established a testing battery to measure the performance of some basic skills in boxing, which included all proposed skill tests were characterized by high factor validity because of their high loading values in a factor which measures a particular domain.
\end{abstract}

Keywords: Factor analysis, Mega-Strike, COUNT-N-TIME

\section{Introduction}

$\mathrm{T}$ The world's attention has increased in recent years for objective tests and effective measurement instruments in the evaluation process because its effective to reach the higher levels of any game or sporting event.

The boxing sport is an important part of Olympic games. Therefore, all organizers of boxing's affairs seek to develop its laws and management based on electronic devices, modern tools, tests and measurement instruments to reach the higher levels in boxing and support scientific planning.

In addition, Boxing sport is one of most important sporting activities in Egypt that assumes full care so it was a part of the courses in various faculties of Physical Education for Boys, military and sports schools. Therefore, the selection students process and evaluation process need to take into account developing their tests and standards.

\section{Research problem}

Through the researcher taught Boxing course at the Faculty of Physical Education in Port Said found that the process of assessing students' skills level based on self- evaluation during the lecture or summative test, which may lack objectivity in some cases, so there is a persistent need to build a battery of objective tests pose equal opportunities for all students to evaluate their performance.

In addition, Through readings of many sources, references and studies related to measuring the skill level in boxing, the researcher found a battery skill test designed by (Ismail et al., 2000), which It has been relied upon in many researches and studies, which help him in designing the current battery as a litmus indicative.

And with developing many technological innovations of instruments in the field of measurement and evaluation of sports in general and boxing in particular. For Examples of such technological devices in boxing Mega-Strike device. The researcher was calibrate this device by using Biomechanics analysis to measure the force of the punch (Rakha, 2013), this device is also used to measure the speed of response. As well as device COUNT-N-TIME to measure the speed of punches, and the speed of combination punches.

Through the foregoing, this research is a serious scientific attempt to recruit potential offered by the technological 
innovations to design a modern technology battery consists of objective tests to measure the skill level in boxing for students at the Faculty of Physical Education.

\section{The research aims}

1- Design some skill tests to measure skill level in boxing for students at the Faculty of Physical Education.

2- Extraction testing battery to measure skill level in boxing for students at the Faculty of Physical Education.

\section{Research question}

1- Is the intercorrelation matrix between the proposed skill tests to measure the skill level in boxing for students of the Faculty of Physical Education "factorable "?

2- What is the extraction testing battery from factorial analysis to measure skill level in boxing for students at the Faculty of Physical Education?

\section{The terminology}

\section{1- Testing Battery}

(Hassanein, 1987) defined testing battery as "a group of several tests are applied respectively by the individual to achieve a desired objective".

\section{2- Factor analysis}

(DeCoster, 1998) defined Factor analysis as a collection of methods used to examine how the underlying constructs influence the responses of a number of measured variables. There are basically two types of factor analysis: exploratory and confirmatory. Exploratory factor analysis (EFA) attempts to discover the nature of the constructs influencing a set of responses. Confirmatory factor analysis (CFA) tests whether a specified set of constructs is influencing responses in a predicted way.

\section{Method}

The researcher used the descriptive method, as this is more suitable for the nature of the research.

\section{Sample Research}

\section{Sample Size}

The researcher selected a sample purposefully from students in second year at Faculty of Physical Education in Port Said for the academic year 2015/2016 AD where already studied the course (Boxing-1for Boys). And from this sample selected randomly (100 students).

\section{The homogeneity of the sample:}

Table (1)

Minimum, Maximum value, Means \& SD of Skewness for weight, height, age \& IQ ( $n=100)$

\begin{tabular}{|c|c|c|c|c|c|c|c|c|}
\hline \multicolumn{2}{|c|}{} & Measurement unit & Minimum & Maximum & Means & \multirow{2}{*}{ SD } & \multicolumn{2}{|c|}{ Skewness } \\
\cline { 5 - 9 } & & & & & Value & Standard error \\
\hline 1 & Height & $\mathrm{Cm}$ & 160.00 & 190.00 & 175.58 & 6.79 & $-.180-$ & .241 \\
\hline 3 & Weight & $\mathrm{Kg}$ & 53.00 & 103.00 & 73.62 & 10.85 & .636 & .241 \\
\hline 4 & Age & Year/day & 20.15 & 23.201 & 21.029 & .80 & .770 & .241 \\
\hline
\end{tabular}

From (Table 1) it is clear that skews values ranged between $( \pm 3)$ reflecting the sample homogeneity on the between (-1.80 and 1.332) for research sample, values variables of weight, height, age, and IQ.

Table (2)

The sample representation Percentages of elite men and youth boy boxers weight categories

\begin{tabular}{|c|c|c|c|c|}
\hline \multicolumn{2}{|c|}{} & Weight Kg & Represent Weight Categories & Represent in sample \% \\
\hline 1 & Light Weights & To $60 \mathrm{Kg}$ & Light Fly, Fly, Bantam \& Light & $16 \%$ \\
\hline 2 & Middle Weights & To $75 \mathrm{Kg}$ & Light Welter, Welter \& Middle & $51 \%$ \\
\hline 3 & Heavy Weights & Over $75 \mathrm{Kg}$ & Light Heavy, Heavy \& Super Heavy & $33 \%$ \\
\hline
\end{tabular}

From (Table 2) it is clear that sample represented all elite men and youth Boy boxers weight categories as the normal distribution. $16 \%$ of the sample represented light Weights (Light Fly, Fly, Bantam \& Light), $51 \%$ of the sample represented middle Weights (Light Welter, Welter $\&$ Middle), and $33 \%$ of the sample represented heavy Weights (Light Heavy, Heavy \& Super Heavy). (AIBA, 2015) 


\section{The Devices and tools used in research}

1- A restameter device to measure the height to nearest $1 / 2$ $\mathrm{cm}$.

2- An electronic scale device to measure weight to nearest $1 / 2 \mathrm{~kg}$.

3- A high intelligence test designed by (Khairy, ND).

4- Mega-Strike device: (Rakha, 2013) calibrated MegaStrike device to measure punching force in boxing through the following:

Momentum $(\mathrm{Mr})=(0.780 \times$ Megastrike value $)+17.90$

$$
F=\frac{M \text { By Regression predictive formula }}{\text { Time from (mega-strike) }} \text {. }
$$

Figure (1)

Mega-Strike device

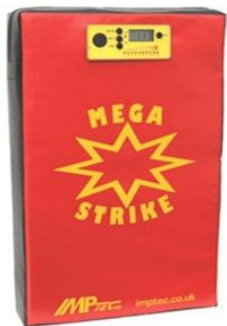

COUNT-N-TIME device

This device is used for the following:

- Counts the number of good strikes in a time period (up to 90 seconds)

- Times a preset number of strikes (up to 990) to nearest 1/10th of a second (up to 99.9 seconds

- Times a preset combination (up to 9 strikes) to nearest $1 / 100$ th of a second
Figure (2)

COUNT-N-TIME device

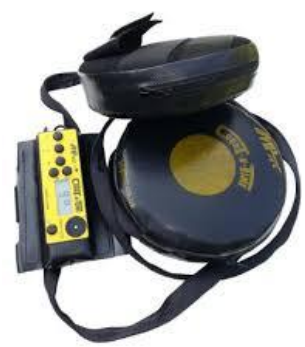

Identify the basic skills in Boxing under research

The researcher identified all basic skills that involved in the course description of Boxing (1) for Second year, Faculty of Physical Education in Port Said, as follows:

1- Stance \& foot work

2- Lead hand straight punch to the head and body (Jab).

3- Backhand straight punch to the head and body (Cross)

4- Combination straight punch (Lead - Backhand, and Backhand- lead)

Determine the appropriate tests to measure basic skills under research

For the purpose of obtaining the appropriate tests of basic skills in Boxing, the researcher has the following:

1- Comprehensive survey of many references and scientific research like, (Sonnenberg, 1996), (Fiedler, 1997), (Frank \& Peter, 1998), (Doug, 1999), (Danna, 2000), (Ismail et al., 2000), (Siegfried \& Ellwanger, 2008), (Rakha, 2009), (Rakha, 2013), (Lissenden, 2013).

2- Using battery skill tests in boxing, designed by (Ismail et al. 2000) as litmus indicator.

3- Using certain electronic devices (Mega-Strike COUNT-N-TIME).

The Reasearcher reached in a number of appropriate tests of basic skills in Boxing. Table 3 shows those tests. 
Table (3)

The appropriate tests to measure basic skills under research

\begin{tabular}{|c|c|c|c|c|c|}
\hline No & Skills & Test & Unit & Test Description & Image \\
\hline 1 & $\begin{array}{l}\text { Stance \& foot } \\
\text { work }\end{array}$ & $\begin{array}{l}\text { Stance \& foot work } \\
\text { evaluation }\end{array}$ & Degree & $\begin{array}{l}\text { Instruments: Performance Evaluation Card } \\
\text { Performance specifications: } \\
\text { The Boxer performing the stands ready and } \\
\text { footwork, the evaluator assesses the performance } \\
\text { of Stance \& foot work according to the criteria } \\
\text { listed in the evaluation card, They are as follows: } \\
\text { The position of the (head - arms and fist - } \\
\text { Rotation of the trunk to the right with a slight } \\
\text { bends forward - Bend the knees with the } \\
\text { distribution of the weight of the body on the feet - } \\
\text { Stand on the rear instep - Maintaining the side } \\
\text { distance - Maintaining distance between the front } \\
\text { and rear foot - Move on harrows - move foot } \\
\text { crawls - Optimum speed and appropriate } \\
\text { performance) } \\
\text { Register: The Evaluator registers the boxer`s } \\
\text { degree from Ten degrees so that takes all the } \\
\text { standard one degree. }\end{array}$ & \\
\hline 2 & $\begin{array}{l}\text { Lead hand } \\
\text { straight punch } \\
\text { to the head } \\
\quad \text { (Jab) }\end{array}$ & $\begin{array}{l}\text { Force Test by Mega- } \\
\text { Strike Device } \\
\text { Speed of response Test } \\
\text { by Mega-Strike Device }\end{array}$ & Newton & $\begin{array}{l}\text { Instruments: Mega-Strike Device } \\
\text { Performance specifications: } \\
\text { Boxer stands and get ready in the long distance } \\
\text { from the Mega Strike device, and when he hears } \\
\text { the beep of device he should perform the }\end{array}$ & \\
\hline 3 & $\begin{array}{l}\text { Lead hand } \\
\text { straight punch } \\
\text { to the body } \\
\quad(\mathrm{Jab})\end{array}$ & $\begin{array}{l}\text { Force Test by Mega- } \\
\text { Strike Device } \\
\text { Speed of response Test } \\
\text { by Mega-Strike Device }\end{array}$ & Newton & $\begin{array}{l}\text { specified punch in the star drawn in the middle of } \\
\text { the device. } \\
\text { Register: } \\
\text { For Force Degree: The evaluator registers the } \\
\text { degree of the mega strike device and then }\end{array}$ & \\
\hline 4 & $\begin{array}{l}\text { Rearhand } \\
\text { straight punch } \\
\text { to the head } \\
\text { (Cross) }\end{array}$ & $\begin{array}{l}\text { Force Test by Mega- } \\
\text { Strike Device } \\
\text { Speed of response Test } \\
\text { by Mega-Strike Device }\end{array}$ & Newton & $\begin{array}{c}\text { following formula: } \\
\mathrm{Mr}=(0.780 \times \text { Megastrike value })+17.90\end{array}$ & \\
\hline 5 & $\begin{array}{l}\text { Rearhand } \\
\text { straight punch } \\
\text { to the body } \\
\text { (Cross) }\end{array}$ & $\begin{array}{l}\text { Force Test by Mega- } \\
\text { Strike Device } \\
\text { Speed of response Test } \\
\text { by Mega-Strike Device }\end{array}$ & Newton & $\begin{array}{l}\text { For speed response The evaluator registers the } \\
\text { speed response (the time from the beep of the } \\
\text { device to the arrival of specified punch in } 1 / \\
\text { 100th of a second). }\end{array}$ & \\
\hline 6 & \multirow[b]{3}{*}{$\begin{array}{l}\text { Combination } \\
\text { straight punch }\end{array}$} & $\begin{array}{l}\text { - The speed of Jab- } \\
\text { Cross combination } \\
\text { punches in the 30th } \\
\text { test }\end{array}$ & Count & \multirow{3}{*}{$\begin{array}{l}\text { - Instruments: COUNT-N-TIME } \\
\text { - Performance specifications: } \\
\text { Boxer stands and get ready in the long distance } \\
\text { from the coach who wears COUNT-N-TIME } \\
\text { device, When the coach gives the signal to start } \\
\text { The Boxer should perform the specified } \\
\text { Combination straight punch } \\
\text { Register: } \\
\text { I- For the speed of Jab-Cross combination } \\
\text { punches in the 30th test: The Evaluator } \\
\text { registers the count of punches that the } \\
\text { boxer had performed in } 30 \text { second. } \\
\text { II- The speed of one (Jab-Cross) or (Jab- } \\
\text { Cross-Jab) combination punch test: The } \\
\text { Evaluator registers the time from the } \\
\text { device in 1/100th of a second. }\end{array}$} & \\
\hline 7 & & $\begin{array}{l}\text { - The speed of one Jab- } \\
\text { Cross combination } \\
\text { punch test }\end{array}$ & $\begin{array}{l}1 / 100 \text { th } \\
\text { of a } \\
\text { second }\end{array}$ & & \\
\hline 8 & & $\begin{array}{c}\text { - The speed of one Jab- } \\
\text { Cross-Jab combination } \\
\text { punch test }\end{array}$ & $\begin{array}{l}1 / 100 \text { th } \\
\text { of a } \\
\text { second }\end{array}$ & & \\
\hline
\end{tabular}




\section{The content validity of proposed skill tests:}

(Bahi, 1999) refers that the content validity is a measure the appropriateness of the test's aspects of the measured components through logically analyzed its elements. To achieve this, the researcher designed a questionnaire about the eight proposed skill tests and presented it to Five experts hold a $\mathrm{PhD}$ degree in Boxing. They have to propose some amendments to the skill tests and agreed $100 \%$ on its ability to measure the skill level and they are suitable conducting a factorial analysis of them, which shows the high content validity of the tests.

The stability and Intrinsic Validity of the proposed skill tests:
To ensure the stability of the proposed tests, the researcher used test - retest method (Bahi, 1999), and conducted the measurements on (20) students from a random sample of the second year students who have studied boxing course (1) in the first semester of the academic year 2015/2016 and outside the core sample. The first measurement was conducted on 9/3/2016 and the second dated 03/15/2016. The researcher adopted $(0.75)$ correlation coefficient and above. The researcher also obtained the intrinsic validity of the tests through the square root of stability factor (Bahi, 1999). In addition, the researcher benefited from this exploratory implementation in explained the tests to assistant team, identified the obstacles that may accompany the implementation, and identified the time it takes to perform.

Table (4)

The stability and Intrinsic Validity of the proposed skill tests

\begin{tabular}{|c|c|c|c|c|c|c|c|c|c|}
\hline \multirow{2}{*}{ No } & \multirow{2}{*}{ Basic Skills Tests } & \multirow{2}{*}{ Unit } & \multicolumn{2}{|c|}{ First Test } & \multicolumn{2}{|c|}{ Second Test } & \multirow{2}{*}{$\mathrm{R}$} & \multirow{2}{*}{$\begin{array}{c}\mathrm{P} \\
\text { value }\end{array}$} & \multirow{2}{*}{$\begin{array}{l}\text { Intrinsic } \\
\text { Validity }\end{array}$} \\
\hline & & & Means & $\mathrm{SD}$ & Means & SD & & & \\
\hline 1 & $\begin{array}{l}\text { Stance \& foot work evaluation } \\
(\mathrm{S} \& \mathrm{FW})\end{array}$ & Degree & 5.70 & 1.62 & 5.65 & 1.66 & 0.894 & 0.00 & 0.945 \\
\hline $2 \mathrm{a}$ & $\begin{array}{l}\text { Lead hand straight punch to the } \\
\text { head (Jab) force Test } \\
\text { (LHSPH_F_test) }\end{array}$ & Newton & 61.05 & 11.33 & 57.83 & 10.97 & 0.949 & 0.00 & 0.974 \\
\hline $2 \mathrm{~b}$ & $\begin{array}{l}\text { Lead hand straight punch to the } \\
\text { head (Jab) speed of response } \\
\text { Test (LHSPH_RS_test) }\end{array}$ & Second & 0.63 & 0.12 & 0.59 & 0.11 & 0.935 & 0.00 & 0.967 \\
\hline $3 a$ & $\begin{array}{l}\text { Rear hand straight punch to the } \\
\text { head (Cross) force Test } \\
\text { (RHSPH_F_test) }\end{array}$ & Newton & 70.52 & 13.47 & $64-80$ & 12.72 & 0.928 & 0.00 & 0.963 \\
\hline $3 b$ & $\begin{array}{l}\text { Rear hand straight punch to the } \\
\text { head (Cross) speed of response } \\
\text { Test (RHSPH_F_test) }\end{array}$ & Second & 0.66 & 0.10 & 0.65 & 0.10 & 0.887 & 0.00 & 0.941 \\
\hline $4 a$ & $\begin{array}{l}\text { Lead hand straight punch to the } \\
\text { body (Jab) force Test } \\
\text { (LHSPB_F_test) }\end{array}$ & Newton & 62.60 & 14.43 & 61.07 & 12.30 & 0.924 & 0.00 & 0.961 \\
\hline $4 \mathrm{~b}$ & $\begin{array}{l}\text { Lead hand straight punch to the } \\
\text { body (Jab) speed of response } \\
\text { Test (LHSPB_RS_test) }\end{array}$ & Second & 0.58 & 0.12 & 0.54 & 0.10 & 0.905 & 0.00 & 0.951 \\
\hline $5 \mathrm{a}$ & $\begin{array}{l}\text { Rear hand straight punch to the } \\
\text { body (Cross) force Test } \\
\text { (RHSPB_F_test) }\end{array}$ & Newton & 73.78 & 13.73 & 73.43 & 12.57 & 0.923 & 0.00 & 0.961 \\
\hline $5 b$ & $\begin{array}{l}\text { Rear hand straight punch to the } \\
\text { body (Cross) speed of response } \\
\text { Test (RHSPB_RS_test) }\end{array}$ & Second & 0.59 & 0.06 & 0.57 & 0.08 & 0.902 & 0.00 & 0.950 \\
\hline 6 & $\begin{array}{l}\text { The speed of Jab-cross } \\
\text { combination punches in the } \\
\text { 30th test (JCCPs_S_30thtest) }\end{array}$ & Counting & 54.60 & 13.44 & 55.10 & 12.37 & 0.929 & 0.00 & 0.964 \\
\hline 7 & $\begin{array}{l}\text { The speed of one Jab-cross } \\
\text { combination punch test (One } \\
\text { JCCPs_S_test) }\end{array}$ & $\begin{array}{l}\text { 1/100th of a } \\
\text { second }\end{array}$ & 0.188 & 0.05 & 0.186 & 0.06 & 0.957 & 0.00 & 0.978 \\
\hline 8 & $\begin{array}{l}\text { The speed of one Jab-Cross-jab } \\
\text { combination punch test (One } \\
\text { JCJPs_S_test) }\end{array}$ & $\begin{array}{l}\text { 1/100th of a } \\
\text { second }\end{array}$ & 0.171 & 0.04 & 0.164 & 0.03 & 0.938 & 0.00 & 0.968 \\
\hline
\end{tabular}


Table (4) shows that the correlation coefficient between the first measuring and the second ranged between $(0.887$ - 0.957) level of significance (0.00), which is significant at the level (0.05), indicating a high stability Coefficient. In addition, the Intrinsic Validity ranged between (0.945 0.978 ) that also indicates a high Intrinsic Validity.

\section{The Basic implementation of the proposed skill tests:}

After confirming the scientific Coefficients and suitability for the research sample, the researcher conducting the basic implementation of the proposed skill tests over the two days 16-17 / 3/2016, where divided the research sample (100 Students) into two equal halves. Fifty students responded to the proposed skills tests per day, The aim of this implementation to verify the discriminatory ability of the tests as well as conduct the factor analysis.

\section{The discriminatory ability of the tests}

Table (5)

Mean, standard deviation and T-test for the two groups in high level and low level $(\mathrm{N}=100)$

\begin{tabular}{|c|l|c|c|c|c|c|c|c|}
\hline \multirow{2}{*}{ No } & \multirow{2}{*}{ Basic Skills Tests } & \multirow{2}{*}{ Unit } & \multicolumn{2}{|c|}{ High Level group } & \multicolumn{2}{|c|}{ Low Level group } & $\begin{array}{c}\text { T-test for } \\
\text { Equality } \\
\text { of Means }\end{array}$ \\
\cline { 4 - 7 } & & & Means & SD & Means & SD \\
\hline 1 & S\&FW & Degree & 8.04 & 0.20 & 3.96 & 0.20 & 72.12 & 0.00 \\
\hline 2a & LHSPH_F_test & Newton & 71.22 & 6.77 & 39.32 & 6.95 & 16.43 & 0.00 \\
\hline 2b & LHSPH_RS_test & Second & 0.53 & 0.50 & 1.01 & 0.16 & -13.87 & 0.00 \\
\hline 3a & RHSPH_F_test & Newton & 86.27 & 5.93 & 46.83 & 10.62 & 16.21 & 0.00 \\
\hline 3b & RHSPH_RS_test & Second & 0.54 & 0.03 & 1.03 & 0.39 & -6.18 & 0.00 \\
\hline 4a & LHSPB_F_test & Newton & 87.49 & 19.30 & 41.85 & 7.55 & 11.01 & 0.00 \\
\hline 4b & LHSPB_RS_test & Second & 0.46 & 0.06 & 0.89 & 0.20 & -10.16 & 0.00 \\
\hline 5a & RHSPB_F_test & Newton & 93.34 & 15.39 & 49.66 & 8.30 & 12.49 & 0.00 \\
\hline $5 b$ & RHSPB_RS_test & Second & 0.53 & 0.04 & 0.86 & 0.12 & -12.23 & 0.00 \\
\hline 6 & JCCPs_S_30thtest & Counting & 79.68 & 6.90 & 40.92 & 1.55 & 27.39 & 0.00 \\
\hline 7 & One JCCPs_S_test & $1 / 100$ th of a second & 0.14 & 0.02 & 0.28 & 0.03 & -16.15 & 0.00 \\
\hline 8 & One JCJCPs_S_test & $1 / 100$ th of a second & 0.15 & 0.02 & 0.31 & 0.05 & -14.55 & 0.00 \\
\hline
\end{tabular}

Table (5) cleared that t-test values ranged $(-16.15,72.12)$ with significance level $(0.00)$, this mean that there is a statistically significant difference in the proposed skill tests between the high and low level group at a significant level (0.05).This result indicates that tests can distinction between high-level and low level .(Allawy \& Radwan, 1988).

\section{Statistical treatment}

correlation coefficient, Intrinsic Validity, T-test, KMO, Bartlett's Test, Factor analysis).

\section{Results}

Present the results of the first question "Is the intercorrelation matrix between the proposed skill tests to measure the skill level in boxing for the students of the Faculty of Physical Education "factorable"?

The researcher used (SPSS.V20) software for conducting following statistical treatments: (Mean, SD, Skewness, 
Table (6)

The correlation matrix of proposed skills tests in boxing tests

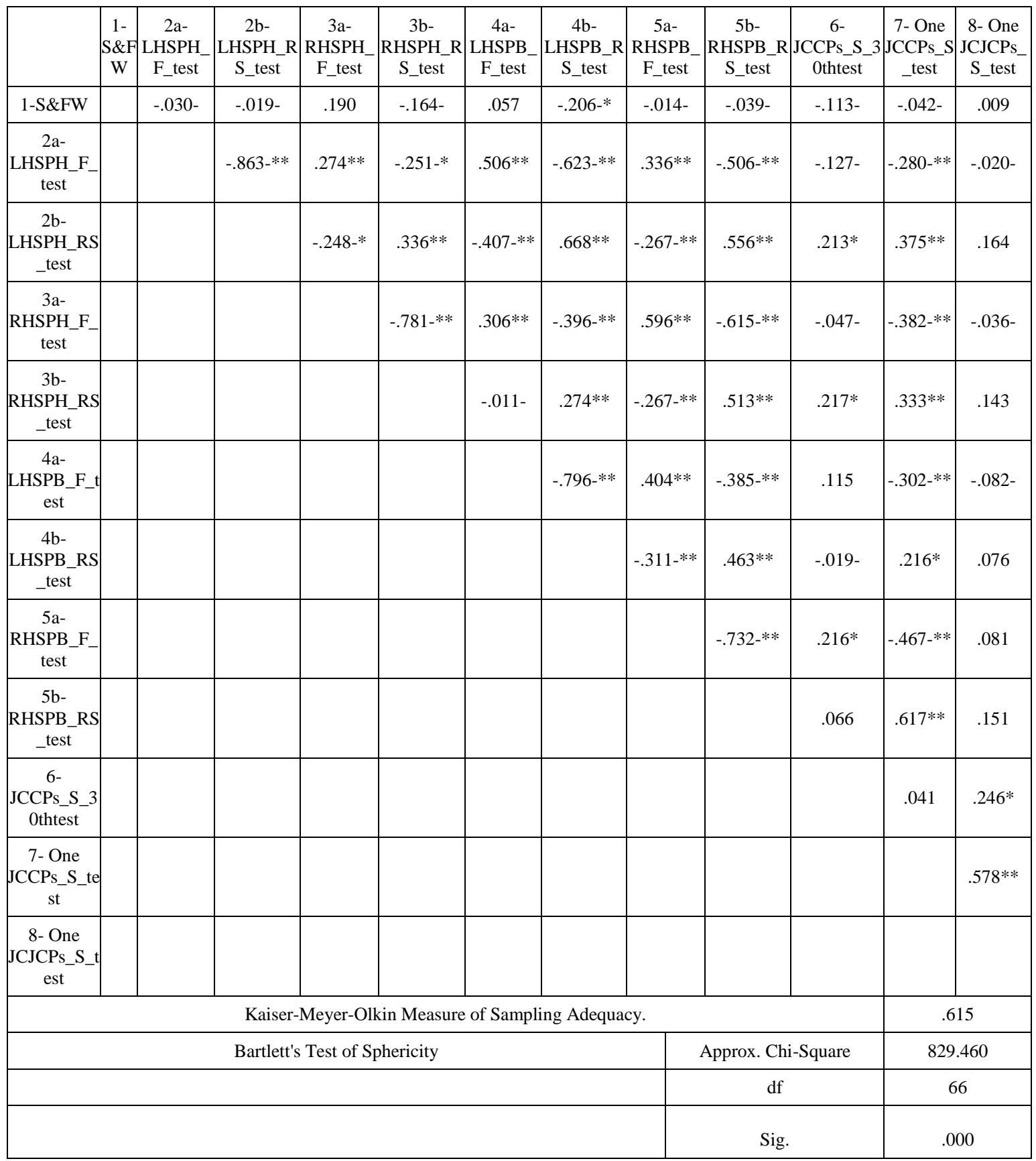

* Correlation is significant at the 0.05 level (2-tailed).** Significant at the 0.01 level (2-tailed)

Table (6) shows the correlation matrix of (12) tests to measure basic skills in boxing, and notes from the table that the matrix contains (66) correlation coefficients (not counted the diameter cells), including:

- (32) positive correlation Coefficients representatives (48.48\%), Four coefficients of them significant at (0.05) level, (16) Coefficient significant at (0.01) level, and (12) correlation coefficients were not significant.

- (34) negative correlation Coefficients representatives $(51.51 \%)$, Three coefficients of them significant at (0.05) level, (16) Coefficients significant at (0.01) level, and (13) correlation coefficients were not significant. 
In addition, Table (6) shows that the value of KaiserMeyer-Olkin (KMO) Measure of Sampling Adequacy reached $(0.615)$ is greater than $(0.50)$ which indicates that sample size (100 students) is suitable to conduct Factor Analysis. As for Bartlett's Test of Sphericity the level of significance reached (0.00) is smaller than (0.05) which indicates that the correlation between the variables are statistically significant, which indicates the validity of data for factor analysis. (Friel, 2010)

Present the results of the second question "What is the extraction testing battery from factorial analysis to measure skill level in boxing for students at the Faculty of Physical Education?
A) Determined the number of Extracted factors from factorial analysis of skill tests before rotation (Initial Solution) by using components Principal method:

The researcher used the principal components analysis (PCA). PCA is a multivariate technique in which a number of related variables are transformed to set of uncorrelated variables (Jackson, 1991). As well as PCA accepts the Kaiser criterion to determine the extracted factors. The Kaiser rule is to drop all components with eigenvalues under 1.0 (Brown, 2015).

Table (7)

Mean, SD, Skewness and the Factor analysis of correlation matrix before rotation (initial solution)

\begin{tabular}{|c|c|c|c|c|c|c|c|c|c|c|}
\hline \multirow{2}{*}{ No } & \multirow{2}{*}{ Tests } & \multicolumn{3}{|c|}{ Descriptive Statistics } & \multirow{2}{*}{ 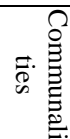 } & \multicolumn{5}{|c|}{ Component } \\
\hline & & Mean & $\mathrm{SD}$ & 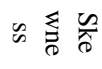 & & 1 & 2 & 3 & 4 & 5 \\
\hline 1 & S\&FW & 5.70 & 1.65 & .287 & .842 & $-.132-$ & $-.161-$ & $-.003-$ & .574 & .685 \\
\hline $2 \mathrm{a}$ & LHSPH_F_test & 56.65 & 12.82 & $-.286-$ & .866 & $-.734-$ & .391 & $-.290-$ & .088 & $-.287-$ \\
\hline $2 b$ & LHSPH_RS_test & .72 & .20 & 1.289 & .878 & .757 & $-.248-$ & .419 & $-.084-$ & .245 \\
\hline $3 a$ & RHSPH_F_test & 66.02 & 15.66 & $-.283-$ & .866 & $-.709-$ & $-.367-$ & .407 & .252 & $-.008-$ \\
\hline $3 b$ & RHSPH_RS_test & .74 & .27 & 1.351 & .829 & .587 & .549 & $-.118-$ & $-.368-$ & .182 \\
\hline $4 a$ & LHSPB_F_test & 62.55 & 19.73 & 1.258 & .816 & $-.642-$ & .514 & $-.010-$ & $-.118-$ & .354 \\
\hline $4 \mathrm{~b}$ & LHSPB_RS_test & .66 & .20 & 1.592 & .877 & .751 & $-.444-$ & .135 & $-.188-$ & $-.249-$ \\
\hline $5 a$ & RHSPB_F_test & 69.54 & 18.50 & 1.007 & .816 & $-.668-$ & $-.007-$ & .559 & -.229 & -.069 \\
\hline $5 b$ & RHSPB_RS_test & .67 & .14 & 1.320 & .818 & .850 & .167 & $-.178-$ & .124 & .141 \\
\hline 6 & JCCPs_S_30thtest & 58.56 & 15.37 & .425 & .722 & .094 & .382 & .634 & $-.350-$ & .206 \\
\hline 7 & One JCCPs_S_test & .20 & .05 & .413 & .893 & .229 & .458 & .549 & .482 & $-.312-$ \\
\hline 8 & One JCJCPs_S_test & .22 & .07 & .909 & .865 & .638 & .389 & .093 & .514 & $-.184-$ \\
\hline \multirow{3}{*}{\multicolumn{2}{|c|}{$\begin{array}{l}\text { Initial Eigenvalues } \\
\text { (Extraction Sums of } \\
\text { Squared Loadings) }\end{array}$}} & & \multicolumn{3}{|c|}{ Total } & 4.59 & 1.67 & 1.51 & 1.28 & 1.03 \\
\hline & & & \multicolumn{3}{|c|}{$\%$ of Variance } & 38.26 & 13.95 & 12.69 & 10.66 & 8.59 \\
\hline & & & \multicolumn{3}{|c|}{ Cumulative $\%$} & 38.26 & 52.20 & 64.82 & 75.48 & 84.07 \\
\hline
\end{tabular}

Extraction Method: Principal Component Analysis.

a. 5 components extracted.

Table (7) shows that all the means larger than standard third factor $(12.69 \%)$, the fourth factor (10.66\%) and fifth deviations for each test separately, as well as that all Skewness values ranging from $( \pm 3)$ which refers to normalization of sample research results in proposed skills tests.

According to the Kaiser criterion, It was extracted five factors which they Initial Eigenvalues more than (1.0) explain $(84.07 \%)$ of Cumulative Variance. As well as noted from the table (6) that the extracted factors in descending order according to their importance as follow: The first factor $(38.26 \%)$, the second factor $(13.95 \%)$, the

factor $(8.59 \%)$.

B) The interpretation of extracting factors after Orthogonal Rotation by Varimax method (final Solution):

In order to get the simple structure for Thurston 1947 to refer to the most readily interpretable solutions, in which each factor is defined by a subset of indicators that load highly on the factor; and each indicator has a high loading on one factor. The researcher used the Orthogonal Rotation by Varimax technique, which constrained the factors are uncorrelated (Brown, 2015). 
Table (8)

Component matrix proposed skills tests after rotating.

\begin{tabular}{|c|c|c|c|c|c|c|c|}
\hline \multirow{2}{*}{ No } & \multirow{2}{*}{\multicolumn{2}{|c|}{ Tests }} & \multicolumn{5}{|c|}{ Component } \\
\hline & & & 1 & 2 & 3 & 4 & 5 \\
\hline 1 & & $\& F W$ & & & & & .907 \\
\hline $2 \mathrm{a}$ & & H_F_test & $-.869-$ & & & & \\
\hline $2 b$ & $\mathrm{LH}$ & H_RS_test & .840 & & & & \\
\hline $3 \mathrm{a}$ & & PH_F_test & & $-.892-$ & & & \\
\hline $3 b$ & $\mathrm{RH}$ & H_RS_test & & .814 & & & \\
\hline $4 a$ & & B_F_test & $-.756-$ & & & & \\
\hline $4 b$ & $\mathrm{LH}$ & B_RS_test & .860 & & & & \\
\hline $5 \mathrm{a}$ & & PB_F_test & & -.699 & & & \\
\hline $5 b$ & $\mathrm{RH}$ & B_RS_test & & .737 & & & \\
\hline 6 & $\mathrm{JCC}$ & _S_30thtest & & & & .830 & \\
\hline 7 & One & CPs_S_test & & & .791 & & \\
\hline 8 & One & JCPs_S_test & & & .917 & & \\
\hline \multirow{3}{*}{\multicolumn{2}{|c|}{$\begin{array}{l}\text { Rotation Sums of } \\
\text { Squared Loadings }\end{array}$}} & Total & 3.091 & 2.829 & 1.616 & 1.427 & 1.126 \\
\hline & & $\%$ of Variance & 25.761 & 23.578 & 13.465 & 11.890 & 9.380 \\
\hline & & Cumulative $\%$ & 25.761 & 49.339 & 62.805 & 74.694 & 84.07 \\
\hline
\end{tabular}

Extraction Method: Principal Component Analysis.

Rotation Method: Varimax with Kaiser Normalization.

Noted from table (8) that loading values of factors may have changed when compared to the values before rotation as well as the Initial Eigenvalues. While the cumulative variance value is maintained in $(84.07 \%)$ and the extracted factors were arising in descending in order of importance. The researcher has retained a test with high loading which is above $( \pm 0.50)$ for each factor. To stand out even skill tests with high loading in the five factors and thus can be interpreted.

\section{i- The interpretation of the First Factor}

Through a table (8) it is clear that the first factor includes four skill tests represent $(25.76 \%)$ of the Cumulative variation, a (Lead hand straight punch to the head force Test, Lead hand straight punch to the head speed of response Test, Lead hand straight punch to the body force Test, and Lead hand straight punch to the body speed of response Test). Loading values of those tests on this factor amounted (-0.869-, 0.840, -0.756-, 0.860) respectively. Therefore, the researcher named the first factor (Lead hand Straight punch-Jab) because it included all types of Lead hand Straight punch which achieved a high loading value.

ii- The interpretation of the Second Factor
Through a table (8) it is clear that the second factor includes four skill tests represent $(23.58 \%)$ of the Cumulative variation, a (Rear hand straight punch to the head force Test, Rear hand straight punch to the head speed of response Test, Rear hand straight punch to the body force Test, Rear hand straight punch to the body speed of response Test) and loading values of those tests on this factor amounted $(-0.892-, 0.814,-0.699-, 0.737)$ respectively. Therefore, the researcher named the second factor (Rear hand Straight punch-Cross) because it included all types of Rear hand Straight punch which achieved a high loading value.

iii- The interpretation of the Third Factor

Through a table (8) it is clear that the third factor includes two skill tests represent $(13.46 \%)$ of the Cumulative variation, a (The speed of one Jab-cross combination punch test, The speed of one Jab-Cross-jab combination punch test) and loading values of those tests on this factor amounted $(0.791,0.917)$ respectively. Therefore, the researcher named the third factor (The speed of one combination punch) because it included the speed of one combination punch tests.

iv- The interpretation of the Fourth Factor 
Through a table (8) it is clear that the fourth factor includes one skill test represent $(11.89 \%)$ of the Cumulative variation, The speed of Jab-cross combination punches in the 30th test and loading value amounted (0.830). Therefore, the researcher named the fourth factor (The speed of Jab-cross combination).

v- The interpretation of the Fifth Factor

Through a table (8) it is clear that the fifth factor includes one skill test represent $(9.38 \%)$ of the Cumulative variation, The Stance \& foot work evaluation test and loading value amounted (0.907). Therefore, the researcher named the fifth factor (The Stance \& foot work evaluation).

\section{Conclusions}

1- In light of the factor analysis using orthogonal rotation, showed five factors have been accepted represent five particular domains cover the basic skills assessed in the Second year, Faculty of Physical Education in Port Said students (course Boxing 1), As follows: (Lead hand Straight punch- Rear hand Straight punch - The speed of one combination punch- The speed of Jab-cross combination punches- Stance $\&$ foot work).

2- Established a testing battery to measure the skill level in boxing for students at the Faculty of Physical Education, which included all proposed skill tests in table (2) because of their high loading values in a factor which measures a particular domain.

\section{Recommendations}

1- Applying the extracted testing battery to measure the skill level in boxing and setting up a standard score tables according to different local environments.

2- Build and develop many testing batteries that use modern technologies in boxing, which measure physical and skills so that help specialists in necessary evaluation processes.

\section{References}

1- AIBA (2015). Technical rules, Retrieved (26 September, 2016) from http://www.aiba.org/aibatechnical-competition-rules/

2- Allawy, Mohamed \& Radwan,Mohamed. (1988). Measurement in physical education and sports psychology, 2nd Ed, Cairo: Dar Al-Fikr Al-Araby.

3- Bahi, Mustafa (1999). Scientific Coefficients between scientific theory and practice. Cairo: Book publishing center.
4- Brown, Timothy A. (2015). Confirmatory Factor Analysis for Applied Research. Second Edition. New York: The Guilford Press. USA.

5- Danna, S. (2000), Boxing The Complete Guide to Training and Fitness, Berkley Publishing Group, New York.

6- DeCoster, J. (1998). Overview of Factor Analysis. Retrieved (29 July, 2016) from http://www.stathelp.com/notes.html

7- Doug, W (1999), Boxer's Start-up: A Beginner's Guide Boxing, Tracks Publishing San Diego, California, USA.

8- Fiedler, Horst (1997), Boxen für Einsteiger Training Technik - Taktik, Sportverlag, Berlin.

9- Frank, K. \& W. Peter. (1998). Fitness Boxing. New York: Sterling Publishing Co.

10- Friel, Charles M. (2010). Notes on Factor Analysis. Criminal Justice Center, Sam Houston State University.

11- Hassanein, Mohamed Sobhi (1987). Methods of construction and legalization of tests and standards in physical education. The second edition. Cairo: Dar ElFeker El-Araby Press.

12- Ismail, Ismail Hamid., Azab, Mohammed Diaa Eddin., Shaalan, Atef Maghawry., \& Ghoneim, Mohamed Abdelaziz. (2000). Boxing education, management \& training. Cairo: Dar El-Saada Press.

13- Jackson, J. Edward, (1991). A User's Guide To Principal Components. A Wiley-Interscience Publication. USA.

14- Khairy, El-Sayed. Mohamed. (ND), a test of higher intelligence, Arab Renaissance Publishing House, Cairo.

15- Lissenden, Hilary. (2013). The Complete Guide to Boxing Fitness: A non-contact boxing training manual. Bloomsbury publishing. Londen.

16- Rakha, Ahmed Hassan.(2009). Educational Software for Learning Boxing, Designing, Preparation. Scenario Building and Execution Phase. Saarbrücken: VDM Verlag.

17- Rakha, Ahmed. (2013). Biomechanical calibration of Mega-strike device to measure the punching force of amateur boxers. The 11th International scientific conference for physical education and movement science - Sport in theory and practice, October 23-25. Faculty of Physical Education. Alexandria University. 
18- Siegfried \& Ellwanger, Ulf. (2008). Boxen Basics, Traning - Technik - Taktik, Pietsch Verlag, Stuttgart , Germany.
19- Sonnenberg, Herbert. (1996). Boxen, Fechten mit der Faust, Verlag Weinmann, Berlin, Germany. 